\title{
Obtain Employment Oriented Personnel Training Program of Engineering Class Specialty
}

\author{
Gao Shuxia ${ }^{1}$, Wang Deyi ${ }^{2} *$, Zhang Peng ${ }^{2}$, Guo Xianjun ${ }^{2}$, Zhang Xiaolong ${ }^{2}$ \\ (1. Department of Opt-electric Information Technology, YanTai University, Yantai 264005, \\ People's Republic of China \\ 2.Department of environment and materials engineering of YanTai university, YanTai264005, \\ People's Republic of China) \\ * Corresponding Author
}

\begin{abstract}
With the development of environmental protection industry, environmental protection equipment manufacturing industry is a growing demand for professionals in the aspects of environmental protection equipment engineering. At the same time, the profession in China just began and many questions such as how to train relevant personals are needed to be further explored. This paper aims at making an analysis and discussing the training of senior environmental protection equipment engineering professionals.
\end{abstract}

Keywords-obtain employment oriented; Personnel training; program; engineering class; specialty

\section{INTRODUCTION}

The environmental protection industry has become a "sunrise industry" with a lively, there is great potential for development in China. For the time, professional engineering and technical personnel in the environmental protection industry in China is mostly from machinery or environmental engineering, which are the two closer profession. Judging from professional knowledge, work adaptability and a comprehensive analysis and problemsolving ability, mechanical engineering graduates due to lack of knowledge of the environmental studies are not familiar with the pollution control of the basic technology, the basic principles and the basic structure of the related equipment. When making design of environmental protection equipment, they are often faced the phenomenon of copying the form without understanding the substance. They will not make the correct choice of the structural design parameters, and cannot be strategically advantageous position to grasp the direction of development and reform of the governance process, let alone to carry out innovative research and design work. But environment engineering graduates mainly accepted expertise in school is the principle and basic structure of the basic method, commonly used equipment, structures, pipe network design basic knowledge related to pollution control technology, mainly from the process point of view access to relevant knowledge, no in-depth studied under environmental protection equipment design and manufacturing, and maintenance management, materials selection during the design and manufacture of environmental protection equipment, structural design and mechanical aspects of the theory is obviously inadequate, poor graphics capabilities, but also not very good to take the equipment debugging and maintenance tasks.

To alleviate the shortage of the status quo of environmental protection equipment design and manufacturing professionals, the Environmental Protection Equipment Engineering professional is added to the new professional directory of the Ministry of Education. As an new professional, there is only five universities open it. Professional Training program slightly not mature enough, and teaching programs in the course layout unreasonable. In this regard, the research investigated the environmental enterprises and universities on the basis of the training program on environmental protection equipment engineering professionals serious thought and research.

\section{ENVIRONMENTAL PROTECTION EQUIPMENT ENGINEERING PROFESSIONAL TRAINING TARGETING}

In the paper Some Thoughts on the Development of Universities, Mr. Yang Shuzi mentioned that Chinese higher education development and reform of the following serious ills: weight the polytechnic light humanities, relight professional basis, heavy books and practice of light, light weight common personality, heavy utilitarian light quality that Chinese higher education should develop a "thick foundation, wide knowledge strong capacity, highquality, wide caliber of talent." [1]

It is believed that the local colleges and universities must take the initiative to adapt to the needs of economic construction and social development, deepen personnel training mode and personnel training program of reform, improve the quality of personnel training. It should reflect the spirit of educational innovation in the reform, full implementation of the Ministry of Education of Teaching Quality and Teaching Reform Project ", adhere to impart knowledge, build capacity and improve the quality and coordination of development efforts to improve students' learning ability, practical ability and creative ability. From the basic trends in the development of higher education and labor market supply and demand trends, the relatively long time frame, the competition between the graduates and other job seekers become more intense. When comparing with the elite schools, major universities, local ordinary colleges and universities in the possession, there is a big gap of many aspects of educational resources of social awareness and influence. The employer recruitment 
holds varying degrees of "level" concept, which determines the local general undergraduate college graduates and key university graduates in the job market at a different starting line . [2] This can potentially increase the difficulty of the graduates of local colleges.

Therefore, the employment-oriented which is to deepen personnel training programs and personnel training mode of reform and to enhance the competitiveness of the graduates has become an inevitable requirement for sustainable development of the local colleges. Based on the above factors, the training goal of environmental protection equipment engineering talent as basic positioning: culture with good scientific quality, master the system of environmental pollution control technology, environmental protection machinery, equipment design and manufacturing expertise and professional competence in environmental protection equipment engineering, applied engineering and technical personnel engaged in the design and manufacture of environmental protection equipment, equipment performance improvement and perfection of the operation and management of environmental protection equipment development and applied research and environmental protection equipment and maintenance work. After graduate, students can work in environmental protection, chemical industry, light industry, medicine, electricity, steel, materials and other industries engaged in the design of environmental protection equipment manufacturing, installation, production management, technology development, equipment, operation management and maintenance .

\section{ENVIRONMENTAL ENGINEERING TALENTS TRAINING PROGRAM FRAMEWORK}

\section{A. Basic principles}

According to the basic orientation of the personnel training objectives, when studying environmental engineering talents training program framework, there are the following three principles :

1) Personnel training programs should have a reasonable value orientation

Firstly, the tasks which to be undertaken by the local ordinary colleges and universities are delivered excellent research and reserve talents for universities or research institutions. Secondly, the transportation for local socioeconomic development is to advanced applications personnel. Therefore, the local colleges and universities should fully reflect the dominant position of students, and will carry out the educational practice in schools, student body means that the education is not only to teach knowledge, but also to take full care of the differences between individuals and targeted individuals.

In the process of curriculum system construction and optimization, in terms of the structural model selection, professional orientation, or from the public courses, academic basic courses, specialized courses, and professional direction to limit the elective and professional of any elective and practice teaching should be give full consideration to the overall development of students and individual differences. Establish a curriculum system that can reflect the education and teaching students to the dominant position of the mechanism. Independent learning, personality development and to provide greater selectivity space.

2) The training plan must pay full attention to the practical teaching

The main task is assumed by the local ordinary colleges and universities is serve for local social and economic development, the mainstream should be applied in training advanced engineering and technical personnel. So in the process of personnel training programs and curriculum system building, it is necessary to pay attention to the relative integrity of the professional and theoretical system , but also not too much emphasis on the theoretical integrity of the system to ignore the students' comprehensive ability and training. Training objectives for the center, firmly grasp the relatively complete disciplines of knowledge and ability to develop these two basic points. In the process of building and optimizing course system, great importance must be attached to the practical teaching, to improve curriculum design, experiment and practice hours and credits of the proportion of the share of the entire training program, to ensure the quality and quantity of practice teaching .

3) Personnel training program should be conducive to the cultivation of the students' academic spirit

Although it does not cultivate the disciplines of academic masters, the training of students should have at least a certain degree of academic ability and scientific ideological level with help of the educational task assumed by the local ordinary colleges and universities. The academic accomplishment of students in everyday learning,the ability of independent thought and spirit of the realm of perception, can make them with a more solid foundation for the theory, the strong practical ability and everything is freely thinking, all this is more valuable when compare with the limited professional knowledge and skills. Their future work may not be in the professional field, but can become an academic spirit of the workers, to the attitude of the scholars to think about the actual work, they would have a higher than the general practitioners ideological perspective and analysis of the problem to problem-solving ideas and methods.

B. Environmental engineering talents training program framework

1) Personnel training program research and technology roadmap

According to personnel training targeting and the principal of personnel training program, to prepare a personnel training program process technology roadmap shown in Figure 1.

2) The basic framework of personnel training program

The basic framework of the school environmental engineering talents training program can be summarized as follows: a main line; two basic points; three echelon of progressive levels four professional teaching module.
a)
A main line

The main line of a culture established in targeting training in environmental protection equipment in the field of environmental protection equipment engineering design and manufacturing, device performance improvement and improvement of environmental protection equipment 
development and applied research and environmental protection equipment, operation and management of environmental engineering talents the main line with the maintenance application of advanced engineering and technical personnel .

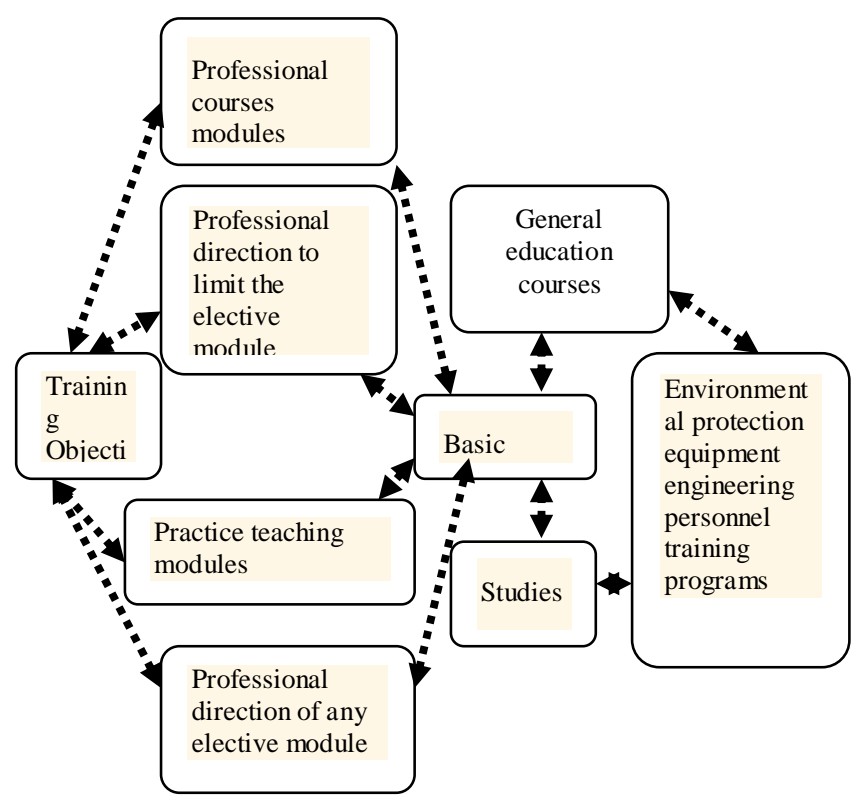

Figure 1. Personnel training research and technology roadmap

b) Two basic points

The basic point is that a relatively complete system of subject knowledge. Subject knowledge the integrity of the system refers to the profession from the personnel training objectives, curriculum structure, academic arrangements, practice teaching a series of personnel training goals teaching elements of the collection, in the abovementioned elements of the curriculum system and practice teaching arrangements are not only the existence of the timing relationships before and after teaching, but also contains the logic of relevance in the teaching, by crisscross, before and after the associated formation of a complete education and teaching network system. It is believed that this complete network system of which not every network node is essential in the curriculum system to build the relative integrity of both, should respect the system of subject knowledge and practice of teaching arrangements, but not be completely shackled by the socalled "system integrity".

Another basic point is the comprehensive ability and quality of the training, comprehensive ability and basic quality of environmental protection equipment engineering, including computer graphics capabilities, the comprehensive experimental ability, the ability of engineering practice, equipment $\mathrm{R} \& \mathrm{D}$ capabilities and innovative thinking ability, and good cultural quality, scientific quality and engineering quality. The formation of the above qualities and capabilities need to be achieved through the subtle influence of the targeted training in the teaching process.

According to the training requirements, the school 's Environmental Protection Equipment Engineering Course consists of three main echelon progressive level is built according to the thick foundation, strong capability and high-quality undergraduate talent. The first level of general education courses and Studies Foundation, this level is to strengthen the basic knowledge, basic theory, basic laboratory capacity and outlook on life, values, such as learning of the basic quality of life and culture. Constitute the second level of the professional foundation courses, the part of the course are determined based on follow-up professional courses to meet learning needs to form a solid basic theory and a strong professional competence, which cannot bite off more than pursuing big, all-embracing. The learning period of students in school is limited after all, not all the knowledge can be imparted to students. The parts of the core curriculum include: engineering graphics and computer graphics, electrical electronics, mechanical engineering, environmental engineering principles, principles and applications of fluid mechanics and fluid machinery, materials, corrosion and protection, machinery manufacturing base, basic mechanical design, mutual change and measurement technology, process Introduction of key industries. The third level consists of four professional teaching modules , including: professional compulsory modules, professional direction to limit the elective modules, professional direction of any of the elective modules and practice teaching modules .$$
\text { d) }
$$

Four professional teaching modules

The school environmental protection equipment engineering include four professional teaching modules from the module of the professional courses, professional direction to limit the elective modules, professional direction of any elective modules and practice of teaching modules. Among them, the professional compulsory modules and professional direction to limit the elective module for students to continue their studies or to work to provide the necessary theoretical knowledge in the learning process to improve analysis and ability to solve practical engineering problems. The two modules of the core curriculum include: water pollution control engineering, air pollution control engineering, solid waste treatment and disposal, welding of metallic materials, instrumentation and automation of environmental engineering. CAD / CAM, environmental protection equipment manufacturing technology, environmental protection equipment principle design, environmental engineering and civil construction.

Professional direction of any elective module can fully reflect the people-centered concept of education, taking into account the overall development of students and individual differences, independent learning, personality development to provide greater selectivity space. Practice teaching module's main task is to improve students' scientific quality, project quality and the comprehensive experimental ability, the ability of engineering practice, equipment $\mathrm{R} \& \mathrm{D}$ capabilities and innovative thinking ability. The modules include: experiments related courses, recognized practice, metalworking, mapping large jobs, electric and electronic training, basic mechanical design course design, 
environmental engineering curriculum design, environmental protection equipment, curriculum design, students' scientific and technological innovation, production internships, graduate internships and graduation project (thesis). The teaching modules of 36 credits, 22 percent of the total credits. Practice of production practice and graduation practice are mainly through the already established eight colleges, enterprises and practice based to complete the other experiments, internships, training and design completed in school.

\section{CONCLUSION}

A lot of research and demonstration have been done, but there are still imperfections. In particular, the employment-oriented research is still quite superficial, and it is hoped that communication with peers can be made about the Environmental Protection Equipment Engineering to make the profession more dynamic, and training more applied engineering and technical personnel for the community .

\section{REFERENCES}

[1] Yang Shuzi stands beforehand, do not abandon beforehand about University - Reflections on the development strategy of $[\mathrm{J}]$. higher education research,1998(1):11-12

[2] Gao Weizhong, on optimizing the teaching local colleges curriculum system $[\mathrm{J}]$. Shaoguan University ( Social Sciences ), 2008,29 (10) :130- 132 .

[3] An Kang. Research on the reform of comprehensive practical training course for the Independent College of vocational standards[J].Higher education of Sciences, 2015(04):82-85.
[4] Xu ErZhong, Ma XiaoQin. Rational thinking on the "application" of the newly established local colleges and Universities[J].Higher education of Sciences, 2014(05):54-58.

[5] paint parvenu, institute organization mode on the basis of general education in the University $[\mathrm{J}]$. Heilongjiang higher education research,2008(10)

[6] high Weizhong, on optimizing teaching of local universities' curriculum system [J]. Journal of Shaoguan University ( SOCIAL SCIENCE ),2008,29(10):130-132.

[7] Wang Defeng, from the perspective of University General Education in the direction and path[J]. Fudan Education Forum,2006,4(4):25-28.

[8] Mei ZhongLei, Liu Min, Yang Fan. Experience and reflection of Guiding Undergraduates to participate in scientific research activities[J].Higher education of Sciences, 2014(03):98-101.

[9] Liu Chunsheng, Zhang Yu. On the occupation education" employment oriented " when to think[J]. Vocational Education Forum,2005,10(28):4-6.

[10] Song Na, Wang QunHui, Li YueFang, Li TianXin. Environmental Engineering Specialty Teaching Reform[J]. China Metallurgical Education.2014(01):31-32.

[11] Hou Pin, Wang JiabBing, Wang ChunRong, Zhang LiPing. Reform of Environmental Engineering Specialty Experiment Teaching in coal University[J].Chinese modern educational equipment, 2015(07)

[12] Li XiaoPing, Feng LinNa. The system construction, reform and practice of the chemical course system of Environmental Science Specialty in Colleges and Universities[J].Higher education of Sciences, 2012(02): 146-150.

[13] Liang Bo. Research on the construction of environmental general education system in Local Undergraduate Colleges[J].Higher education of Sciences, 2014(06):82-86. 